\title{
Characterization of Powder Obtained from Surface of Waste-Plastic Bricks
}

\author{
Rutticka Kedare \\ PG Student, Fergusson College
}

\begin{abstract}
The basic aim of this work is to perform characterization of the powder obtained from surface of waste plastic brick which in turn provides a base to study the physical and chemical composition of bricks made from waste plastic bags and sand (Plastic bricks). The powder used for characterization was obtained from the surface of waste plastic bricks by scratching the surface of bricks with knife-like stainless-steel instruments. Before characterization, this powder was strained through a double layer strainer (mesh number 325, pore size 44 microns) to obtain fine powder particles. This fine powder was further characterised for determining the particle size, crystallinity percentage, elemental composition and to find functional groups present. The techniques used in characterization of powder includes X-ray Diffraction (XRD), Fourier Transform Infrared Spectroscopy (FTIR) and Field Emission Scanning Electron Microscopy / Energy Dispersive X-ray Spectroscopy (FESEM/EDS). The results obtained from XRD data analysis showed the particle size to be 9.595 nanometres with a crystallinity percentage of 2.113275 percent. EDS and FTIR results when studied simultaneously showed presence of clay minerals like $\mathrm{MgO}, \mathrm{SiO} 2, \mathrm{Al2O3}$, etc. Another observation was the noticeable percent of Antimony present in sample which can be traced to either an impurity in sand used or due to colorants present in plastic bags used.
\end{abstract}

Keywords:- Waste-Plastic Bags, Plastic bricks, X-ray Diffraction, FESEM/EDS, FTIR, Spectroscopy.

\section{INTRODUCTION}

RISING use in the amount of plastic waste pose a major threat to our ever-increasing economy. Due to costly and less effective alternatives to plastic bags no such decrease in the use of LDPE bags can be seen even after its ban in many countries. According to Central Pollution Control Board survey in 2018 India generates almost 25,940 tonnes of waste in the form of different types of plastic that too every day. Out of this the companies process only 60 percent of plastic waste while remaining 40 percent remains as it is in dumping grounds or stay littered in rivers or on roads. Even though single use plastic bags production is banned in our country yet their place is still dominant in this 40 percent of waste plastic. To come up with an effective solution we tried transforming these waste plastic bags into bricks that can be used for pavements. We chose waste plastic bags mainly because they are so thin that when we try recycling them, they get stuck in cutters and hence are discarded from most of the plastic recycling. These plastic bags were collected from houses and from roads in our localities and were sorted to be used for manufacturing bricks. After carrying out physical testing on the bricks they were found to be less reactive towards acids and salts along with noticeable compressive strength of approximately $12 \mathrm{~N} / \mathrm{mm} 2$. These bricks were also found to have negligible water absorption. To understand the chemical composition of bricks we carried out further characterisation like XRD, FESEM-EDS and FTIR. From XRD we were able to calculate grain size of particles present in powder obtained from brick surface. We also studied crystallinity percent, elements present in this brick material, dominant functional groups present and could also find out molecules present in the brick material. This study can help us understand the material of brick at molecular and elemental level. 


\section{SAMPLE PREPARATION}

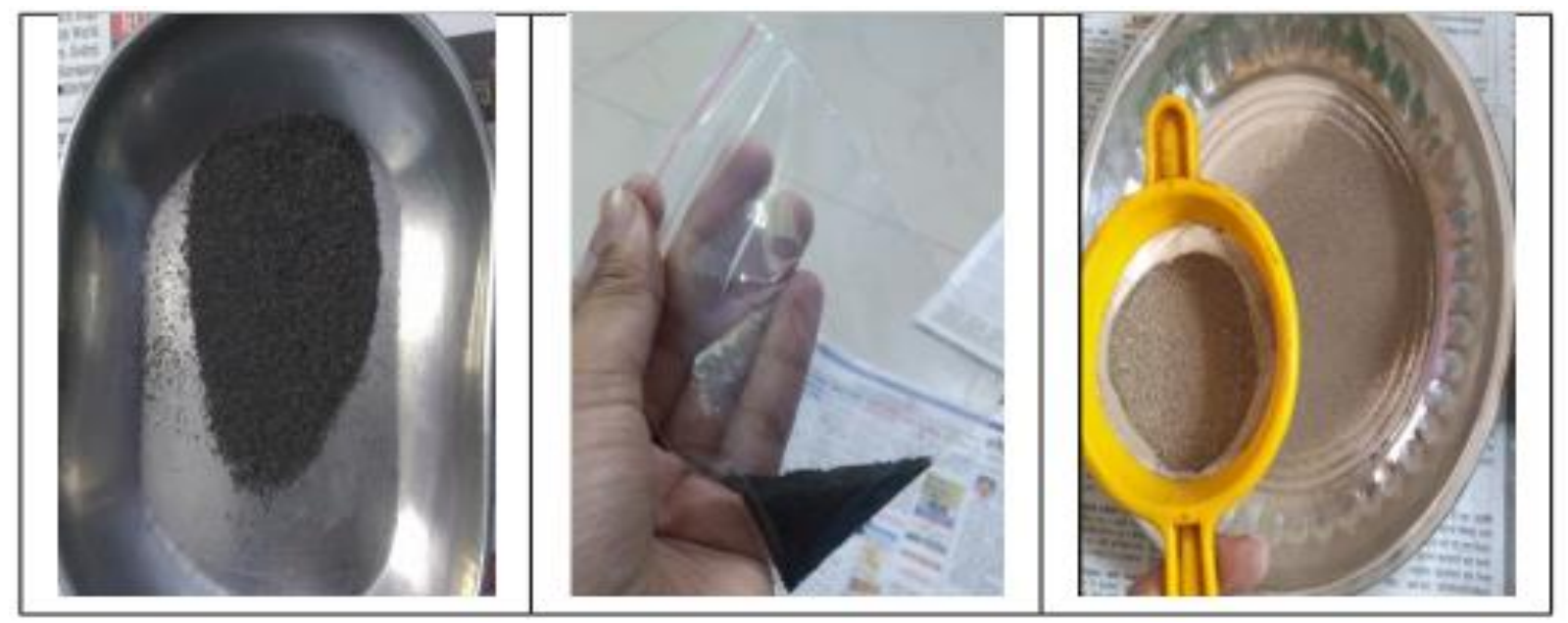

Fig 1:- a) strained brick powder step 1, b) strained brick powder step 2, c) straining of sand.

The powder used for characterisation was obtained by scratching the surface of plastic bricks. The brick was prepared by heating the plastic at a temperature near to its melting point but making sure that temperature do not affect chemical composition of waste plastic largely and only turns the plastic into semi-liquid fluid. Sand was later added in this melt and then we poured this mixture into moulds to give them desired shape.[1] This powder was then strained using a double layer strainer of pore size 44 microns i.e. mesh number 325. After straining we obtained a fine powder which was later characterised under X-rays for obtaining an XRD pattern, FESEM images and EDS spectrum. Samples for each of these characterisation methods were individually prepared as per standard methods.

\section{METHODOLOGIES}

\section{A. X-ray Diffraction (XRD)}

In this the powder sample is kept in a small petri dish which is placed inside a sample holder. The sample holder is placed exactly in the middle portion between the X-ray source and detector. X-rays are pointed onto powder particles which when reflected are collected into detector kept in either Bragg-Brentano geometry or parallel beam. XRD study on powder was conducted at XRD laboratory in Physics Department of Savitribai Phule Pune University. For obtaining XRD pattern, Bruker D8 Advanced [2] diffractometer was used. It was used in Bragg-Brentano geometrical arrangement. The least count rate for detector was 50 million cps and was used in resolution such as to cover 2 theta in wide area. The diffraction was performed in scanning mode. In results we obtained graphs of Intensities plotted against 2 theta which was later analysed in Origin Lab Software. By plotting the Intensities against 2theta in Origin lab, we first performed Gaussian Curve fitting using the tools present in software to soften the data and also to reduce noise, which means less significant and unwanted peaks, from the data. We further focused on peaks with high intensities to find values of Full Width Half Maxima (FWHM). These values of FWHM were later put into
Scherrer equation for further calculations. For calculations we used Bragg's law and Scherrer equation for crystallography.

Bragg's Law: 2dsin = n . - (1)

Scherrer Equation: Crystallite size $(\mathrm{t})=(\mathrm{k}) /(\cos ) .-(2)$

Here, is wavelength of X-ray and its value is considered to be $1.54 \mathrm{~A}, \mathrm{n}$ is a positive integer, is Bragg's angle i.e. ${ }^{\circ}$ the angle between incident ray and the scatter plane, $d$ is the distance between adjacent planes i.e. interplanar distance, $\mathrm{t}$ is the crystallite or particle size, is the value of FWHM, $\mathrm{k}$ is Scherrer's constant which is considered to be 0.9 . [3]

\section{B. Fourier Transform Infrared Spectroscopy (FTIR)}

When the sample is irradiated with Infrared Radiation some radiation is absorbed by the molecules present in the sample and remaining is transmitted or passes through the sample. This resulting IR radiation is captured by the detector which plots the transmittance percentage against wave number. In Fourier Transform IR spectroscopy the resulting spectrum can be classified as transmission spectrum or absorption spectrum depending up on whether we are interested in measuring the amount of light absorbed or the amount of light transmitted. In transmitted spectrum the region between 400 to $1500 \mathrm{~cm} 1$ is called as fingerprint region while the region between 1500 to $400000 \mathrm{~cm}-1$ is an important region during study because in this region most of the stretching frequencies for molecules can be observed. In present study we have focused on transmitted spectrum generated by the powder sample since it can be directly measured while for absorption spectrum some calculations are needed to be done. The wave numbers having high intensities in resulting spectrum were noted and then compared with standard IR results. Study was carried on Bruker Tensor 37 FTIR at Chemistry Department of Savitribai Phule Pune University. 


\section{Field Emission Scanning Electron Microscopy (FESEM)}

This study was also conducted at Central Instrumentation Facility in Savitribai Phule Pune University, Pune, Maharashtra. [6] Tests were conducted on FEI Nova Nano SEM 450 which can work with in lens TLD, BSE and SE detection. Images were captured at different resolutions using xT microscope Control software. In this an electron gun of scanning electron microscope probes surface of particles with very high voltage beam of electrons giving out images on screens. The images can be captured with varying resolutions from 500x to up to $100000 x$. Each of these magnification serves a unique purpose. The images obtained at $5000 \mathrm{x}$ and $1000 \mathrm{x}$ were further used in EDS analysis.

\section{Energy Dispersive X-ray Spectroscopy (EDS)}

We use this technique to identify the elements present in the substance under study. In this the sample is irradiated with a strong beam of X-ray which knocks out few electrons from the atoms present in sample, thus giving away a characteristic X-ray pattern which is captured by the detector. The results for this are obtained in the form of EDS spectrum. The number of X-rays (counts per second) are recorded against voltage applied in kilo electron volts
$(\mathrm{keV})$. The results obtained were in unnormalized and normalized concentration in weight percent of element. For the present study we focused on atomic weight percentages. Most of the characteristic X-rays observed were in $\mathrm{K}$ series except for antimony that gave emission in L-series. EDS analysis was carried on Bruker XFlash 6130 that has element detection range between $4 \mathrm{Be}$ and $95 \mathrm{Am}$. Its energy resolution ranges between $45 \mathrm{eV}$ at $\mathrm{C} \mathrm{K}$ and $123 \mathrm{eV}$ at $\mathrm{Mn} \mathrm{K}$. For present study two separate images taken at 5002 magnification, with High Voltage of $10.0 \mathrm{kV}$ and range of $75 \mathrm{~nm}$. For each image, we plotted two EDS spectra in Espirit 1.9 software. This study was conducted at Central Instrumentation Facility in Savitribai Phule Pune University, Pune, Maharashtra. [6]

\section{RESULTS}

\section{A. X-ray Diffraction}

After performing calculations using Scherrer Equation the particle size for grains was found to be 9.595 nanometres. The average inter-planar distance was calculated to be 2.596 nanometres and Lattice constant is found to be $0.593 \mathrm{~A}$. The ${ }^{\circ}$ crystallinity percent of powder was calculated to be only 2.113275 percent which is very low thus telling that the powder is mostly amorphous.

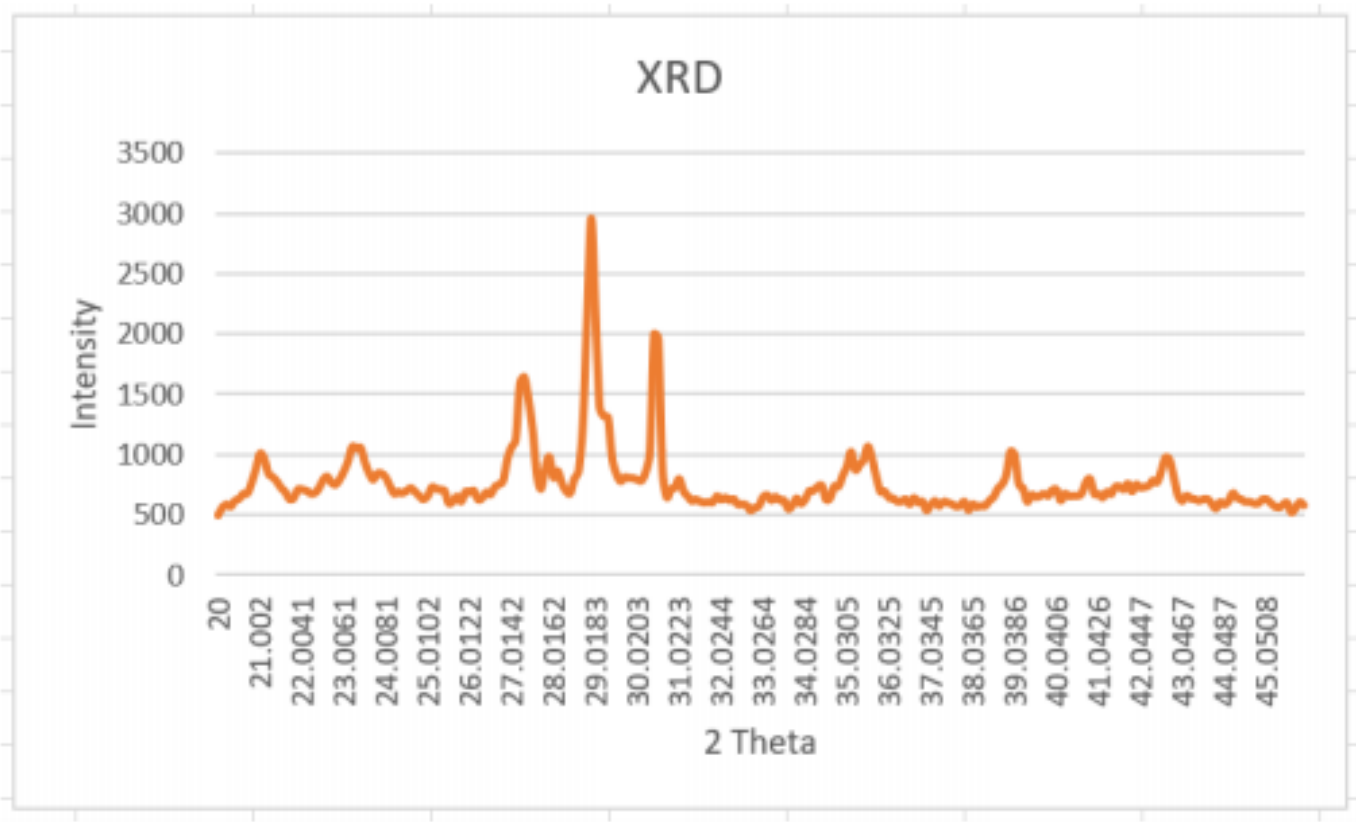

Fig 2:- XRD pattern of Powder obtained from surface of brick 


\section{B. Field Emission Scanning Electron Microscopy}
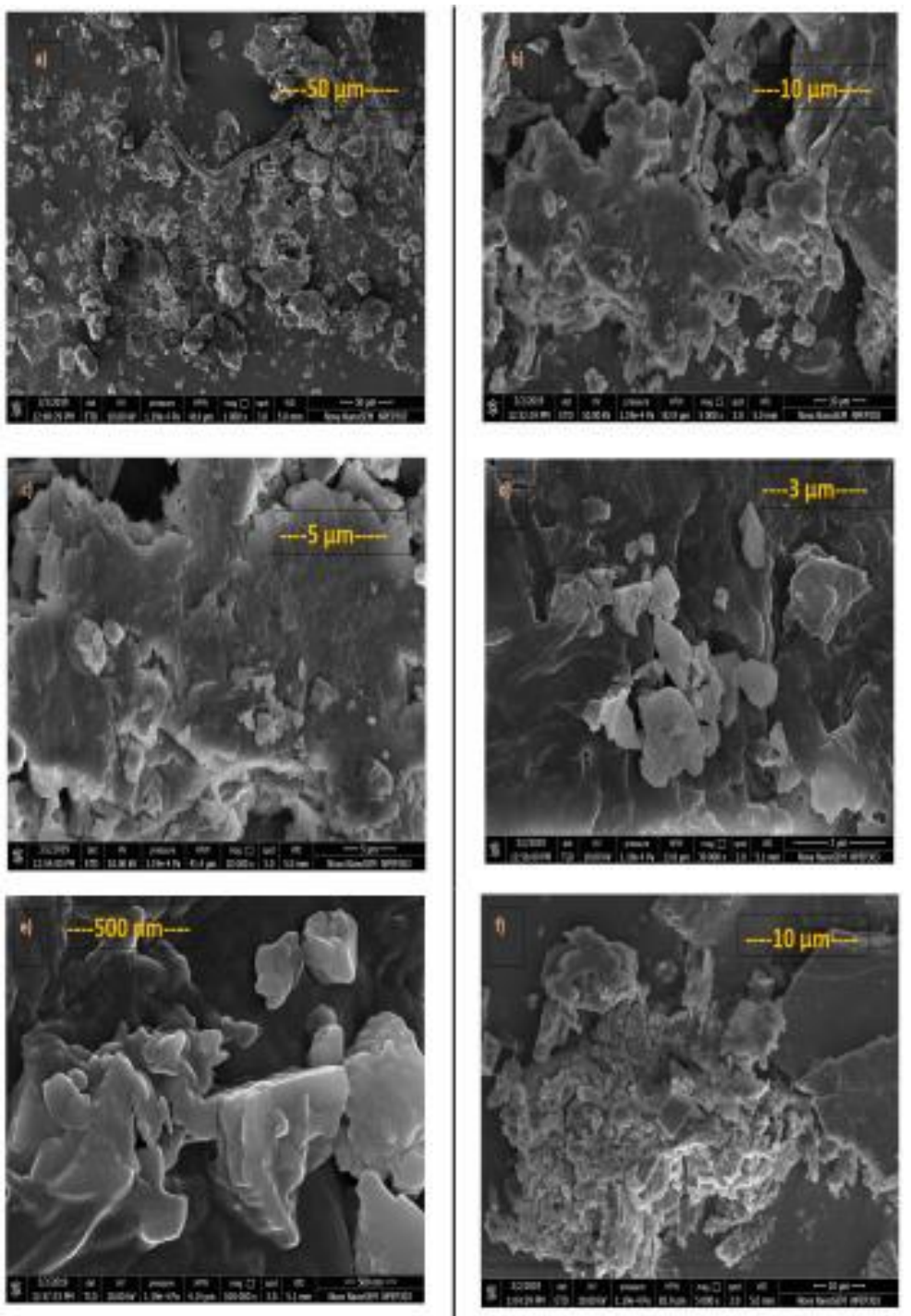

Fig 3:- FESEM image of brick powder at a) 1000 X Magnification, b) 5000 X Magnification (minor agglomerations), c) 10000 X Magnification, d) 30000 X Magnification, e) 100000 X Magnification, f) 5000 X Magnification.

FESEM images were captured by changing the resolution varying from 1000x to 100000x. The images captured at 10000x and 30000x show presence of agglomeration in powder particles which can be formed during heating process. Such agglomeration is generally observed when the plastic bags were not evenly heated in first stage itself or were heated without shredding. In these small pieces of plastic would roll up into balls like structures on which other plastic content (heated or newly added) or sand particles would stick upon thus keeping the inner plastic insulated from proper heating. No specific shapes or structures can be seen in images indicating amorphous nature of powder. In some images the few powder particles appear to be flaky in nature while few other in granular shapes. The granular particles can be traced from presence of sand particles while agglomerated ones maybe due to wrapping of plastic particles on sand/plastic particles during the process of heating. 


\section{Energy Dispersive X-ray Spectroscopy}

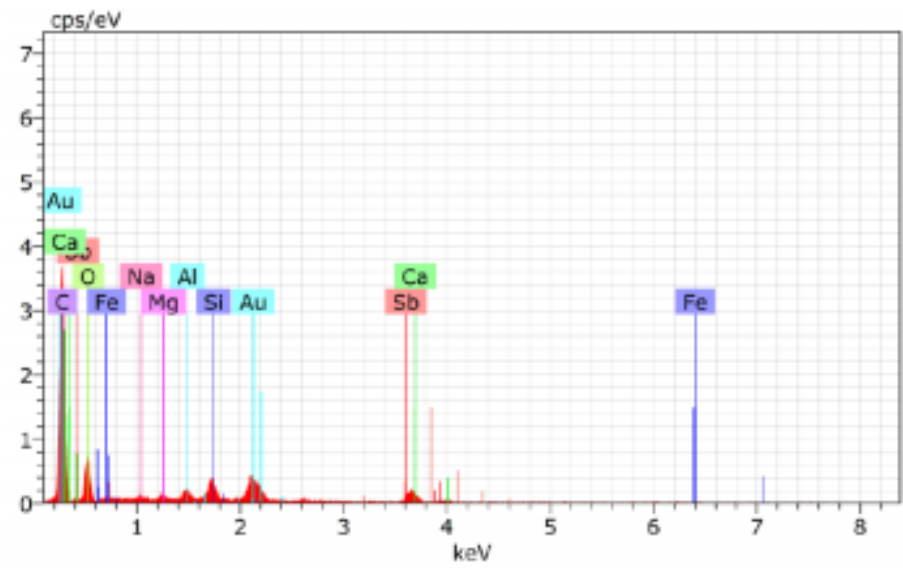

Fig 4:- EDS spectra of powder obtained from brick surface

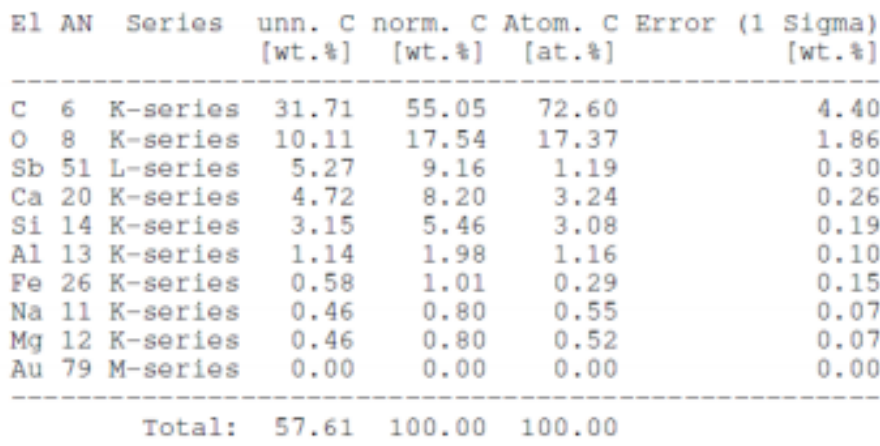

Fig 5:- EDS results obtained after analysis

EDS results showed high elemental percentage of Carbon and Oxygen (since the brick was made from waste plastic bags of polyethylene, a hydrocarbon chain) followed by Silicon (which comes from the sand ( $\mathrm{SiO} 2)$ used in preparation of bricks). Few other metal elements like Aluminium $(\mathrm{Al})$ and Iron $(\mathrm{Fe})$ were present in approximately 5 percent of whole while others like Magnesium ( $\mathrm{Mg}$ ) and Sodium $(\mathrm{Na})$ were present in trace amounts with less than 1 percent of whole. Another element named antimony was found in less percentage i.e. approximately 0.4 to 0.5 percent but the source of it is not properly understood.

\section{Fourier Transform Infrared Spectroscopy}

\begin{tabular}{|c|c|}
\hline IR Frequency in cm-1 & Functional Group \\
\hline 2916 & $\begin{array}{l}\mathrm{C}-\mathrm{H} \text { asymmetric stretching } \\
\text { (unique identification for Polyethylene) }\end{array}$ \\
\hline 2847 & $\begin{array}{l}\text { C-H symmetric stretching } \\
\text { (unique identification for Polyethylene) }\end{array}$ \\
\hline $\begin{array}{l}1573.24 \\
\text { (weak) }\end{array}$ & $\mathrm{N}-\mathrm{O}$ stretch \\
\hline $\begin{array}{l}1416.42 \\
\text { (strong) }\end{array}$ & $\mathrm{CH} 2$ deformation / $\mathrm{CH} 2$ bend \\
\hline 1015.59 & $\begin{array}{l}\text { Si-O-Al VI } \\
\text { (Al in octahedral co-ordination of clay } \\
\text { minerals) }\end{array}$ \\
\hline 575.49 & $\mathrm{C}-\mathrm{C}-\mathrm{C}$ in plane bending \\
\hline
\end{tabular}

Table 1:- Units for Magnetic Properties 
The resultant spectrum of FTIR showed six intense peaks belonging to six different wave numbers as follows, each of these wave numbers indicate presence of specific functional groups. The first two peaks $(2916 \mathrm{~cm}-1$ and $2847 \mathrm{~cm}-1)$ are unique indication for virgin polyethylene. [10] The peak $1461.42 \mathrm{~cm}-1$ which is unique identification of $\mathrm{CH} 2$ deformation / bending in molecule.[7] $1573.24 \mathrm{~cm}-1$ peak is weak in spectrum but indicates presence of N-O bond.[8] The peaks $1015.59 \mathrm{~cm}-1$ and 575.49 cm-1 both belong to finger print region indicating clay mineral molecule and C-C-C bending in plane respectively.[11] 1015.59 cm-1 indicate presence of Aluminium in octahedral co-ordination with Silicon like clay mineral. [9]

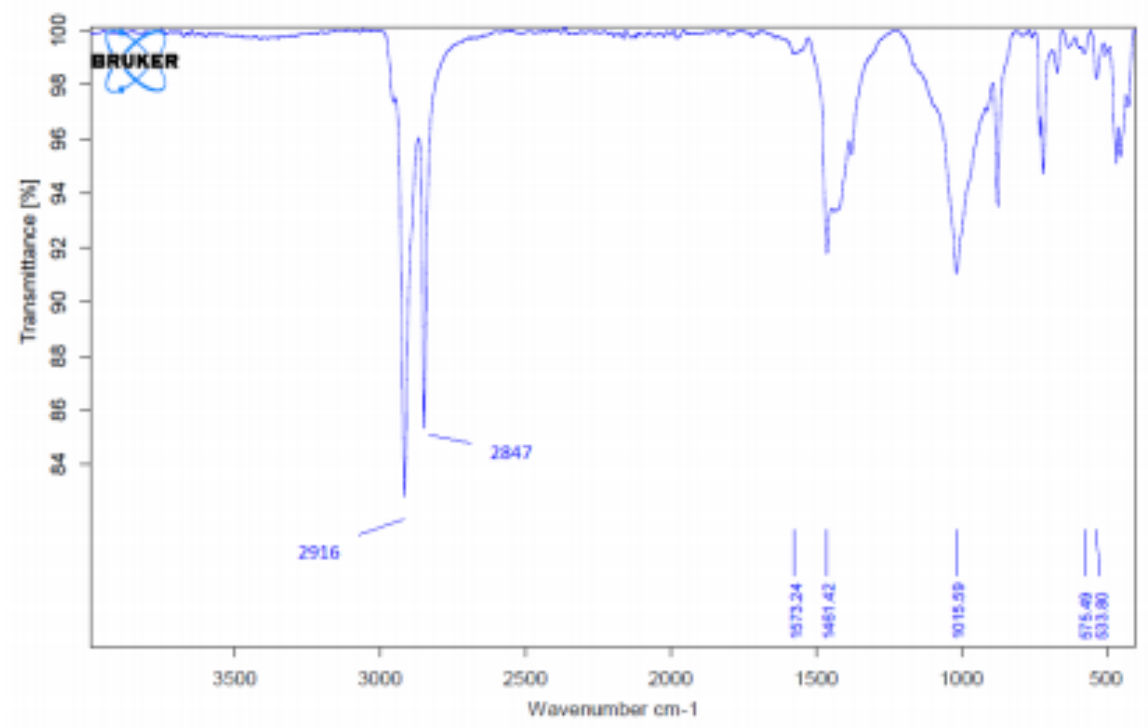

Fig 6:- FTIR Spectra of powder obtained from brick surface

\section{CONCLUSION AND FUTURE WORK}

The XRD results prove that the particles in powder obtained from the surface of waste plastic bricks are of the size of nanometres. This Brick is made up of waste plastic bags and manufactured sand. The temperatures at which the brick was manufactured was around 150-200 degree Celsius which is not large enough to break the bonds between sand particles but good enough to break polymer chains in LDPE plastic i.e. a plastic bag, thus, converting it into a lower alkane. From this study we can conclude that when LDPE is heated at temperature above its melting point (105 degree Celsius) even the waste plastic bag is transformed into nanoparticles, which is another proof of hazard that burning plastic bags in open poses. The powder is mostly amorphous in nature with very low crystallinity percentage. SEM images too showed no specific structure formations in images other than minor agglomerations, thus confirming amorphous nature of powder. FTIR and EDS results confirm presence of clay minerals like $\mathrm{MgO}, \mathrm{SiO}$, $\mathrm{Al} 2 \mathrm{O} 3, \mathrm{Fe} 2 \mathrm{O} 3, \mathrm{Na} 2 \mathrm{O}$ and $\mathrm{CaO}$ along with minor elemental quantities of Antimony. This presence of antimony was found in EDS results of sand as well. So, we can conclude that the antimony either came from the impurities present in manufactured sand used for manufacturing of brick or because of colorants that are used during manufacture of plastics.

\section{FUTURE WORK}

Since the crystallinity percent is very low the explanation for interplanar spacing can be given as the spacing between planes of small range crystalline order as we find in amorphous substances. Also, the high intensity broader peaks that determine the nanoparticle nature of powder can otherwise be explained as an average of all the intensities captured by detector when amorphous substance scattered x-ray in all directions. To understand whether the results obtain indicate crystalline nature or amorphous nature we can perform Reitveld analysis [4] on same database with the use of MAUD software. Better understanding of elemental composition change can be studied by performing EDS and FTIR analysis on Sand, Waste plastic bags and the powder under study. It can help us get insight about changes in molecular arrangements before and after brick making.

\section{REFERENCES}

[1]. Kedare, R. (2020). "Physical Characterisation of Waste Plastic bricks and Development of Material for Pothole filling", International Journal of Scientific Development and Research, vol.5, Issue 1, p. 38-42.

[2]. "The D8 Advanced Family", X-ray Diffraction, X-ray Diffraction and Elemental Analysis, Products, Bruker, viewed on March 18, 2020 at https://www.bruker.com/products/X-ray-diffractionand-elementalanalysis/x-ray-diffraction/d8advance.htmlffraction/d8-advance.html 
[3]. "Field Emission Scanning Electron Microscopy (FESEM) - Energy Dispersive Spectroscopy (EDS)", Central Instrumentation Facility, SPPU. http://cif.unipune.ac.in/index.php/services/fesem-eds

[4]. Groenen, R., Lieberman, V and Hege, K. (2007). "A substrate coated with amorphous hydrogenated carbon", Patent no. WO2009080610A1 viewed on March 20, $2020 \quad$ at https://patents.google.com/patent/WO2009080610A1/ en

[5]. Jordi, M. (2014). "FTIR for Identification of Contamination", Case Study, Jordi Labs LLC. Viewed on March 20, 2020 at https://jordilabs.com/wpcontent/uploads/2014/09/Case StudyF T IRF orI dentif icationOfC ontamination.pdf

[6]. "IR Spectroscopy Tutorial: Nitro groups" viewed on March 20, $2020 \quad$ at https://www.orgchemboulder.com/Spectroscopy/irtuto r/nitrosir.shtml

[7]. Aayisha, S., Devi, T., Janani, S., Muthu, S., Raja, M. and Hemamalini, R. (2019). "Structural (PES), AIM, spectroscopic profiling (FT-IR, FTRaman, NMR and UV), HOMO-LUMO and docking studies of 2,2dimethyl-N-(2-pyridinyl) propanamide - a DFT approach", Chemical Data Collections, Science Direct, Elsevier viewed on March 14, 2020 at https://doi.org/10.1016/j.cdc.2019.100287.

[8]. Oikonomopoulos, I., Tougiannidis, N., Perraki, T and Gurk, M. (2016). "Mineralogical characterization of the intraseam layers of Lofoi lignite deposits in Florina basin (western Makedonia, northwest Greece)", Energy Sources, Part A: Recovery, Utilization, and Environmental Effects, vol.38, no.11, p. $1562-1568$.

[9]. Lutterotti, L., "Introduction to Diffraction and the Reitveld Method", Laboratorio Sciencza E Technologia Dei Materiali viewed on March 20, 2020 at http://www.ing.unitn.it/ luttero/laboratoriomateriali/RietveldRefinements.pdfrc es, Part A: Recovery, Utilization, and Environmental Effects, vol.38, no.11, p. 1562-1568.

[10]. Kittel, C. (2016). "Wave Diffraction and the Reciprocal Lattice" in Introduction to Solid State Physics, Eighth Edition, p.23-45.

[11]. Cullity B. and Stock, S. (2014). Chapter 3: Diffraction I: Geometry in "Elements of X-ray Diffraction", Third Edition, Pearson New International Edition. p. 91-124.

[12]. Gnanasaravanan, S. and Rajkumar, B. (2013). "Characterization of minerals in natural and manufactured sand in Cauvery River belt, Tamilnadu , India”, Infrared Physics and Technology 58, p.21-31.

[13]. Kutchko, B. and Kim, A. (2006). "Fly ash characterization by SEM-EDS", Fuel 85, Science Direct, Elsevier, p.2537-2544. 